\title{
An Existential Perspective on Addiction Treatment: A Logic-Based Therapy Case Study
}

\section{Guy du Plessis}

Guy du Plessis, MA, is an addictions counselor, research consultant for the I-System Institute for Transdisciplinary Studies at Utah State University, adjunct professor in the School of Behavioural Sciences at California Southern University, and a faculty member at the Wayne Institute for Advanced Psychotherapy at Bellarmine University. He is the author of An Integral Guide to Recovery: Twelve Steps and Beyond (Integral Publishers), and An Integral Foundation for Addiction Treatment: Beyond the Biopsychosocial Model (Integral Publishers), and co-author of Mind-Body Workbook for Addiction: Effective Tools for Relapse Prevention and Recovery (New Harbinger). He has published research articles in the fields of addiction studies, theoretical psychology and philosophy.

\begin{abstract}
In this essay I argue that a comprehensive understanding of addiction and its treatment should include an existential perspective. I provide a brief overview of an existential perspective of addiction and recovery, which will contextualize the remainder of the essay. I then present a case study of how the six-step philosophical practice method of Logic-Based Therapy can assist with issues that often arise in addiction treatment framed through an existential perspective.
\end{abstract}

Addiction, whatever its form, has always been a desperate search, on a false and hopeless path, for the fulfilment of human freedom.

- Medard Boss (1983, p. 283)

All theories of addiction, whether implicitly or explicitly expressed, have ontological and epistemological foundational suppositions (Richardson, 2005; Slife, 2005). ${ }^{12}$ These foundational

\footnotetext{
${ }^{1}$ Questions of an ontological and epistemological nature usually relate to what is known as a person's Weltanschauung or worldview (Slife 2005).

${ }^{2}$ In this essay the term addiction and substance use disorders will be used interchangeably. Although the term addiction refers to a broader category of behaviour, this essay will limit its discussion to substances use disorders as defined in the Diagnostic and Statistical Manual of Mental Disorders, Fifth Edition (American Psychiatric Association, 2013).
} 
suppositions significantly influence the trajectory of the advancement of the construct of addiction and the nature of its interventions (Richardson 2005). Yet, in addictionology, these initial suppositions are frequently not noticed or just uncritically accepted (Ribes-Inesta, 2003; Du Plessis 2014a; 2014b). Hill (2010), conducted a study to explore the ontological foundation of the major categories of etiological models of addiction and found that most of these models "shared unity at the ontological level" (p. 5). His assessment of these wide categories of addiction shows that positivist or abstractionist ontology is dominant. Slife and Richardson (2008) explained abstractionism as a manner of viewing the world that recognises or regards all ontological reality as independent and isolated. From the abstractionist perspective, addiction is perceived as 'consistent regardless of the context in which the individual is found' (Hill 2010: 16). The same holds true for integrative or compound models like the biopsychosocial model. ${ }^{3}$

Existential psychiatrist Medard Boss (1983) pointed out that an abstractionist perspective has its limitations in explaining the human realm and is only sovereign in the nonhuman realm (natural sciences). He is of the opinion that those that apply an abstractionist foundation to studying the human or social sciences "largely overlook how radically the nature of their object of study - human reality - differs from the make-up of every other realm known to us" (Boss, 1983, p. xxix). He believed that in Freud's metapsychology and most other theories of human existence, there is inevitably an abstraction and tapering from our lived engagement in-theworld; in other words, human being-in-the-world reduced to lower orders of ontic complexity. ${ }^{4}$ Boss (1983) suggested that in addition to a natural scientific perspective we also need an existential foundation to truly understand what it means to be human and what psychopathology is.

Similarly, in this essay I argue (and as I have done elsewhere, see Du Plessis, 2015, 2016, 2018) that an adequate understanding of addiction and recovery should be informed by an existential understanding of human nature, otherwise we remain prone to reducing our being-in-

\footnotetext{
${ }^{3}$ Even though the biopsychosocial model (Griffiths 2005), acknowledges multiple factors in addiction it 'does not automatically eliminate [its] fundamentally abstractionists' assumptions [abstractionist use of de-contextualism, reductionism, and determinism]' (Hill 2010, p. 107), and consequently it "has not explained how the integration of biological, psychological, sociological and behavioural components occur' (DiClimente 2003, p. 18)

4 Boss's approach of Daseinsanalysis, could be described as an ontic articulation of existential philosopher Martin Heidegger's (1962/1927) ontology of Being.
} 
the-world to its constitute parts and consequently, and will likely miss the big picture. ${ }^{5}$ I will provide a brief overview of an existential perspective/foundation of addiction and recovery, which will contextualize the essay. ${ }^{6}$ In the remainder of the essay, and what will be the main focus, I will present a case study of how Logic-Based Therapy, a philosophical counselling method, can assist with existential issues that often arise in addiction treatment. ${ }^{7}$

\section{An Existential Perspective of Addiction and its Treatment}

The term existential perspective or foundation can be misleading if not adequately defined. For the purpose of this essay, an existential perspective refers to the insights of existential philosophy, existential phenomenology, existential psychology, and existential therapy.

Existential philosophy is often associated with philosophers such as Soren Kierkegaard, Friedrich Nietzsche, Martin Heidegger, and Jean-Paul Sartre. These philosophers dealt with the troubled relationship between man and existence. Kierkegaard (1849/1954) examined his own existence through his existential anxiety, and he found this "angst" has a more potent and drastic reality than any concept. Nietzsche (1883/1954) tried to free man from religious and metaphysical consolations by proclaiming, “God is dead.” Heidegger (1927/1962) revolutionized Western ontology by characterizing man as "being-in-the-world" (Dasein), thus, destroying the noted Cartesian aphorism, “I think, therefore I am." Sartre (1943/1971) declared that humans are radically free. Sartre found life to be defined by nothingness, but he believed that man could derive subjective meaning through ownership of one's choices and that man needs a personally meaningful project in order to live.

\footnotetext{
5 I have previously proposed that it is important to situate an existential perspective within a larger metatheoretical framework otherwise it many result in the same reductionism it attempts to critique. I proposed such an integrative metaparadigmatic heuristic, through the application of a critical or pragmatic realism (Harre \& Moghaddam 2012; Bhaskar 1997; 1998) and integral pluralism (Wilber 1995; 2006), could help to address the conceptual challenges in addiction theory and treatment. In short, this heuristic points out that various explanatory views 'co-arise' depending on methodology (methodological pluralism) which 'enacts' a particular reality of addiction (ontological pluralism and complexity), while being mediated by the worldview of the subject applying the method (epistemological pluralism) (see Du Plessis 2012; 2013; 2014a; 2014b 2018). This is not to be confused with a social constructionist position or epistemic relativism.

${ }^{6}$ It is beyond the scope of this essay to provide a comprehensive discussion of an existential perspective of addiction and recovery, and I will only focus on some features that are relevant to the discussion presented in this essay. Please note that these are my interpretations of an existential approach to addiction and recovery; other scholars may have significantly different interpretations. This section of the article as well as some other sections are derived from my book An Integral Foundation for Addiction: Beyond the Biopsychosocial Model (Du Plessis, 2018).

${ }^{7}$ An earlier version of this essay was submitted as the practical assignment of the Primary Certificate Training Course at the Logic-Based Therapy and Consulting Institute. I am grateful to Elliot Cohen for his editing suggestions in the first draft of the essay.
} 
Existential phenomenology is a form of philosophy that emerged primarily from the combination of existential philosophy and phenomenology. Existentialists and phenomenologists placed special emphasis on man's relational openness with his surroundings (the other). Husserl (1901/1973) said that our thoughts have intentionality, in other words they always refer to something, and are related to objects. It is this openness for the other, in the thought of both existential and phenomenological thinkers, that gave rise to a natural merger between these two schools of thought.

The central idea of existential philosophy is the concept "existence," which indicates that our being is essentially and always openness to the other. A central idea of phenomenology is that of "intentionality," by which is meant that our consciousness is always consciousness-of-something, i.e., it is interwoven with the other. Precisely because these fundamental ideas are common to existentialism and phenomenology, these two streams of thought have been able to merge into a single stream as existential phenomenology. (Kwant, 1965, p. 23)

Existential psychology developed at a time when behaviorism and the application of the natural scientific method to psychology and psychotherapy was dominant (May, 1953). The existential psychology approach can be understood as a reaction against this scientific reductionism or abstractionism (applying natural scientific methods) when trying to understand and describe the human and social sciences.

Yalom (1980) notes that the scientific tradition has focused too intently on breaking down a complex organism into its parts. These parts, even when combined do not explain the whole. Such research is often found to be inapplicable and inappropriate in explaining the meaning of what the individual is dealing with as it does not focus on the entire subjective experience, rather, on singular aspects of psychic structure. (Temple and Gall, 2016, p. 4)

Existential therapy began to emerge in the 20th century with the work of such thinkers as Ludwig Binswanger, Otto Rank, Medard Boss, Viktor Frank1, Rollo May, Karl Jaspers, and Irvin Yalom (Cooper, 2003). ${ }^{8}$ For example, Frankl (1953) drew from his experience in a concentration camp during World War II in formalizing his logotherapy approach, which centres on man's

\footnotetext{
${ }^{8}$ For an excellent introduction to existential psychotherapy see Hans Cohn's (1997) Existential Thought and Therapeutic Practice: An Introduction to Existential Psychotherapy. London, England: Sage.
} 
search for meaning. Holding meaninglessness as the central sickness of the modern world, Frankl's logotherapy approach centered on man's will to meaning. May (1953) translated key concepts of existential psychology into psychotherapeutic practice, which helped transition the philosophy from Europe to North America. Yalom (1980), who wrote an essential text on existential psychotherapy, cantered his existential approach on the four ultimate concerns of clients (death, freedom, existential isolation, and meaninglessness). ${ }^{9}$

Existential givens: A central issue in addiction treatment and recovery is how an individual deal with the existential anxiety that arises when confronting ultimate concerns or existential givens. Moreover, addictive behavior can also be understood as a dysfunctional way of dealing with the anxiety induced by a confrontation of existential givens. It is imperative that an individual in recovery finds healthy ways to confront the givens of existence.

There are certain aspects of life that are within our capacity to control and manipulate, but there are also aspects that are given and cannot be avoided; we are "thrown" into these circumstances (Heidegger, 1927/1962). For Yalom (1980), the most significant givens of existence are the unavoidable freedom to choose the way we live our lives, the unavoidability of death, our social isolation, and the meaninglessness of life. For Yalom, the confrontation with these existential givens may evoke anxiety that we often try to circumvent or suppress. What distinguishes existential anxiety from neurotic anxiety, is that all people share the former, it is ontological in nature (Cooper, 2003).

In addiction, the existential anxiety generated with a confrontation with these four existential givens is even further magnified. In active addiction, the threat of death is ever present, and many addicts have friends that have died as a result of addiction. Addiction isolates the individual in a pursuit that is ultimately meaningless where the capacity to choose is inhibited by the powerlessness over the substance and/or behavior. The experience of meaninglessness has been shown to develop into depression and substance abuse (Moore \& Goldner-Vukov, 2009).

\footnotetext{
${ }^{9}$ Temple and Gall (2016) described the current status of existential therapy by stating that it can be "thought of in four different approaches or schools from which various training programs have emerged" (p. 4). (1) Daseinsanalysis (Boss, 1983) which is largely influenced by Heidegger's writings; (2) logotherapy which was developed by Viktor Frankl (1992) and aims to help clients discover the meaning and purpose in their lives (Cooper, 2003); (3) the British school of existential psychotherapy and is based largely on the writings of R. D. Laing and pioneered primarily by Emmy van Deurzen (Cooper, 2003); and (4) the "American approach" and which includes the existential-humanistic approach established by Rollo May, who acted as mentor to James Bugental, Irving Yalom, and Kirk Schneider" (Temple and Gall, 2016, p. 4).
} 
In the next section of the article I will discuss how the existential anxiety generated by a confrontation of certain of these existential givens, particularly that of freedom (and its limitations) can be dealt with using a method of psychological counselling.

\section{Overview of Logic-Based Therapy}

Logic-Based Therapy (LBT) is a form of a philosophical counselling method ${ }^{10}$ developed $^{-1}$ by Elliot Cohen $(2003,2007,2013)$. He states that, "The keynote of the theory is that counselees disturb themselves emotionally and behaviorally by deducing self-defeating, unrealistic conclusions from irrational premises in their practical reasoning. LBT accordingly provides the critical thinking tools for constructing counselees' faulty reasoning; identifying and refuting its irrational premises; and constructing philosophically enlightened antidotes to these premises, guided by a corresponding set of "transcendent virtues..." (Cohen, 2013, p. ix).

Simply put, LBT assists a counselee in improving psychological flexibility and resilience. Psychological flexibility refers to an individual's ability to the extent to which a person can cope with changes in circumstances and think about problems and tasks in novel, creative ways. Psychological resilience is defined as an individual's ability to successfully adapt to life tasks in the face of social disadvantage or other highly adverse conditions.

Apart from the LBT counsellor/consulting helping counselees refute fallacious thinking the counselee is taught metacognitive skills that improves metacognition. Metacognition can be understood as an individual's ability to critically analyse how they think, having relatively high self-awareness and control over their thoughts and developing appropriate thinking strategies at daily living. "LBT accordingly provides the critical thinking tools for constructing counselees' faulty reasoning; identifying and refuting its irrational premises; and constructing philosophically enlightened antidotes to these premises, guided by a corresponding set of "transcendent virtues"... (Cohen, 2013, p. ix).

It is important to note that LBT should not be understood as a psychological approach, because these approaches "look for causal explanations for mental processes whereas LBT examines logical arguments for their soundness... It is thus a humanities discipline whereas psychological approaches are social science approaches. Broadly speaking, the humanities are

\footnotetext{
${ }^{10}$ LBT can also be understood as a type of integrative metatheory of individual and human functioning. A metatheory can simply be understood as referring to a type of super-theory built from overarching constructs that organize and subsume more local, discipline-specific theories and concepts. Edwards (2008a) wrote, "The 'data' of metatheory is not found within this empirical layer of sense-making but within the 'unit-theories' themselves (i.e., the individual theories that are the focus of study for metatheorists)" (p. 65).
} 
interested in epistemic justification, that is, the justification of knowledge and value claims. The social sciences seek to find the causal laws that determine mental processes" (Cohen, 2016, xxii).

The methodology of LBT is defined in six steps: (1) Identify the emotional reasoning; (2) check for fallacies in the premises; (3) refute any fallacy; (4) identify the guiding virtue for each fallacy; (5) find an uplifting philosophy that promotes the guiding virtue; and (6) apply the philosophy by implementing a plan of action for the client. According to Cohen (2016) these "six steps provide a rational framework for confronting problems of living" (xix).

LBT presents a transdiagnostic metaphysics in the sense that is based on the premise that fallacious thinking is a common factor underlying many emotional and behavioral problems. Transdiagnostic interventions can be seen as those that apply the same underlying treatment principles across mental disorders, without tailoring the protocol to specific diagnoses. Emerging literature on transdiagnostic processes has illustrated the benefits of honing in on common psychological processes that underlie clinical syndromes rather than focusing on discrete diagnostic entities (McEvoy, Nathan, \& Norton, 2009).

For example, case formulation models offer limited guidance on how to identify specific mechanisms that are believed to underlie presenting problems, and how to select from the everincreasing treatment options to best target those mechanisms (McEvoy, Nathan, \& Norton, 2009). Without a sound orientating framework this can result in syncretism, where therapists haphazardly pick techniques without any overall rationale and this consequently, results in syncretistic confusion. Consequently, the value of an effective and theoretically sound transdiagnostic intervention cannot be overstated. ${ }^{11}$

Because LBT is informed by rational emotive behaviour therapy (Ellis, 1994) and cognitive behaviour therapy principles it applies similar methodologies as many of the "third wave behaviour therapies' like acceptance and commitment therapy (Hayes, 2005), dialectical

\footnotetext{
${ }^{11}$ A recent publication by Ho and Nakamura (2017) could potentially support the transdiagnostic applications of LBT. In their paper they present an affect-object generative inference and regulation (AGIR) model, and propose that functional dynamics between two systems, the affect-object thought generation system and the cognitive control system, can guide an individual to achieve homeostasis within self and harmonious relationships with others. Their hypothesis is that a "hallmark of mind-body wellbeing can be characterized as a low-frequency anti-correlation between 1) the cognitive control system including the dorsal anterior/middle cingulate cortex, and 2) the affectobject thought generation system including the ventromedial prefrontal cortex and posterior cingulate cortex" (Ho and Nakamura, 2017, p. 137). They propose that the existence of unrealistic "self-centered embodied expectations of self and others" (p. 17) significantly impair mind-body well-being. In LBT parlance these "self-centered expectations" are referred to as the unrealistic "shoulds" and "musts" which underlie many of the cardinal fallacies that propagates unproductive thinking, emotions and behavior.
} 
behavior therapy (Linehan, 1993), and mindfulness-based interventions. ${ }^{12}$ Although LBT shares a similarity to many of these third wave behavior therapies, there are significant epistemological and methodological differences. For example, in mindfulness-based interventions the focus is teaching patients to adopt a 'decentered' perspective of their thoughts as 'mental events'. Instead, in LBT the focus is to teach clients how to adopt a metacognitive perceptive of the psycho-logical mechanisms that cause dysfunctional behaviour and what further makes this method uniquely distinctive is the application of guiding virtues and philosophical antidotes. Instead of merely identifying fallacies and refuting faulty thinking it provides a powerful counterpoint to these points of view.

In the context of addiction recovery, these guiding virtues and philosophical antidotes of LBT could also serve an underlying psychodynamic purpose for recovering addicts. Many addicts suffer from various degrees of pathological narcissism, which can be understood as the regression/fixation to the stage of the archaic, nuclear self. The narcissistically regressed/fixated individual often has a need for omnipotent control, a characteristic of the grandiose self. In active addiction, such power is sought through fusion with an omnipotent self-object (drug of choice) and manifests as impulsivity (Kohut, 1971, 1977). Once in recovery, this need for control will initially manifest as the obsessive-compulsive personality traits of ritual and rigidity. Without some clear recovery structure (and guiding virtues and philosophical antidotes can be part of this recovery structure) and the absence of the previously idealized self-object (drug/s of choice), the narcissistically regressed individual will be subject to massive anxiety, stemming from fear of fragmentation of self and empty depression, which reflects the scantiness of psychic structure and good internal objects. The internalization of guiding virtues (which share many similarities to the 'spiritual principles' in 12 Step programs) can help satisfy the need for ritual and rigidity in a healthy way and once this recovery structure is internalized, it will help build much needed psychic structure (Du Plessis, 2015, 2018). I will discuss this in more depth later in the essay.

Cohen (n.d.) points out that although LBT has a clearly outlined and sequential methodology and that it is not rigid and dogmatic and requires a fair degree of meta-philosophical creativity on the part of the LBT counsellor/consultant. He states that

The philosophical theories LBT utilizes are sundry and diverse... Which of these theories are put into practice is largely a function of what is congenial for the counselee, that is what

\footnotetext{
12 Mindfulness-based intervention (MBI) is a general term for mind-body interventions that focus on the power of "mental training" in regulating mental and physical health conditions. The category of MBI includes MindfulnessBased Stress Reduction (MBSR) and Mindfulness-Based Cognitive Therapy (MBCT) (Shapero et al., 2018).
} 
resonates with his own intellectual lights. So, within broad limits of rationality (as defined by LBT's list of fallacies) and of what is likely to work for individual counselees, LBT avoids proselytizing for particular philosophical views. (p. 3)

It is refreshing to note the emphasis LBT places on willpower, which in itself can be seen as a guiding virtue and philosophical antidote to the deterministic bias that prevails in psychotherapeutic models, the social determinism that underlies studies in the human and social sciences, and the victimhood mentality that is so pervasive in contemporary culture (Du Plessis, in press). Cohen (2016) states that LBT

maintains that people have the capacity to exercise willpower in order to make constructive changes in their lives...This includes, within limits, the ability to overcome tendencies to overreact behaviorally and emotionally to external events; as well as the ability to suspend, or change primary emotional responses to situations that may be creating problems for clients (for example, traumatic events). (p. 176)

\section{A Logic-Based Therapy Case Study}

In the following section of the essay I will present a brief description of an LBT session conducted with a client whom I was counselling for a substance use disorder. ${ }^{13}$ My client, Alwin (not his real name), is a 48 year-old lawyer. After an initial assessment, it became clear he suffered from a cocaine use disorder (APA, 2013). One of Alwin's main obstacles to recovery is his struggle in admitting that he cannot adequately control his cocaine use. As somebody that is seemingly, as he states "in control of all areas of my life" and is a successful professional, the idea of being out of control in certain areas of his life fills him with dread and anxiety; and furthermore this prospect of being out of control is a threat to his self-esteem and view of himself as a successful human being. What complicates the issue further is that he is abstinent for significant periods of time where he feels in control, but as soon as he starts using, his drug use spirals out of control rapidly. ${ }^{14}$

\footnotetext{
13 At the time of the session I was completing a Primary Certificate Training in LBT, and a case study was needed as part of my training. I explained to my client that I was not proficient in LBT and that it was part of my training and that the session would be offered free of charge.

14 The issue of lack of control as a defining issue of addiction is a contentious issue in debates of addiction, as well as in the field of philosophy of action. In this essay I do not wish to enter into debates of determinism and free will, or whether loss of control is indeed a central feature of addictive disorders (APA, 2013).
} 
International Journal of Philosophical Practice Volume 5, Number 1, Winter 2019

\section{Step One: Identify the emotional reasoning}

The first step of LBT can generally be described as Socratic and phenomenological (Cohen, 2016). It is Socratic in the sense that it is a dialogue consisting of open-ended questions, and phenomenological in the sense that it focusses on the experiences and interpretations of the counselee. Cohen (n.d.) describes this step as one "in which the counselor attempts to get inside and resonate with the counselee's subjective world so that she is better able to help the counselee bring the relevant data to the fore...[it] gives the counselee an opportunity to describe, phenomenologically, how he is feeling" (p. 4).

This first step consists of two sub-steps: (1) finding the elements of the counselee's emotional reasoning; and (2) constructing the practical syllogism comprising the counselee's emotional reasoning.

Finding the elements of the counselee's emotional reasoning. Cohen (2016) identifies emotional reasoning as, an emotion (E) that defined by its rating $(\mathrm{R})$ and its intentional object (O), thus obtaining the following formula: $\mathrm{E}=(\mathrm{O}+\mathrm{R})$. The notion of an intentional object is related to the idea of intentionality of Husserl (1901/1973) which proposes that our consciousness or awareness is directional, it is always conscious of an object, where it is personal like our emotions or bodily sensations or others or objects in the world.

During my dialogues with Alwin, his intentional object began to emerge. It became clear that he has trouble accepting the limitations of his control over his use of cocaine. He firmly believes that he should be in control of his using and cannot accept that he is out of control. For him lack of control creates a sense of shame, and he operates under the assumption that he should be in control at all times. For him lack of control in his life equates failure. There are several more aspects to his reasoning, but for the sake of simplicity I will only focus on this one aspect of his emotional reasoning. Alwin expressed that, "If I cannot control my drug use it means I am a failure. Only losers cannot control themselves". The emotions that I identified during the conversation with Alwin were anxiety, shame and fear.

Emotional and behavioural reasoning is unique to human beings (as far as we know). Heidegger (1945) uses the expression Dasein to refer to the experience of being that is peculiar to human beings. Heidegger's account of Dasein includes an analysis of the structure of "care" as such. Care is the a priori transcendental condition for, and thus shows up pre-ontologically in, the everyday phenomenon of mood. According to Heidegger's analysis, I am always in some mood or other. Heidegger argues that moods are not inner subjective colorings laid over an 
objectively given world. These "moods" are often determined by our emotional and behavioural reasoning. It could be said that "moods" influenced by fallacious emotional and behavioural reasoning contributes to what Heidegger calls "fallen-ness" where we exist inauthentically by uncritically accepting our view of ourselves, others and the world.

Constructing the practical syllogism comprising the counselee's emotional reasoning. According to LBT, the arguments that underlie our emotions and behaviors are what Aristotle refers to as practical syllogisms, which possesses the standard form of the syllogism, i.e., major premise (rule), minor premise (report), and conclusion; and the conclusion is a practical outcome (an emotion and/or behaviour).

In constructing the syllogism underlying Alwin's emotional reasoning I will apply the form of a deductive inference (modus ponens), which can be stated in terms of the intentional object $(\mathrm{O})$ and rating $(\mathrm{R})$ of the emotion:

(Rule) If $\mathrm{O}$ then $\mathrm{R}$

(Report) $\mathrm{O}$

(Conclusion) Therefore R

In Alwin's case the intentional object is what he is fearful and anxious about (not being able to control his drug use). The rating is how the intentional object is evaluated by Alwin (being a failure). Thus:

(Rule 1) If I am not in control of my life then I'm a failure.

(Report) If I am not in control of my drug, then I am not in control of all areas of my life. (Conclusion) If I am not in control of my drug, then I'm a failure.

It is often the case that the rule premises of emotional reasoning are deduced from other higher-order rules. Based the above syllogism of Alwin's emotional reasoning I helped him to reveal a more general syllogism, namely, a demand to be in control of all areas of his life:

(Rule-2) I must be in control of (all areas of) my life.

(Rule 1) If I am not in control of my life then I'm a failure.

(Report) If I am not in control of my drug, then I am not in control of all areas of my life. (Conclusion) If I am not in control of my drug, then I'm a failure. 
International Journal of Philosophical Practice Volume 5, Number 1, Winter 2019

Once I was satisfied that I have exposed the higher order premises underpinning Alwin's emotional reasoning, I moved on to the next step of identifying irrational premises.

\section{Step Two: Check for fallacies in the premises}

In this step, the counselor identifies the fallacies in the counselee's premises. The cardinal fallacies I identified from my dialogue with Alwin are demanding perfection and damnation (damnation of self).

Alwin's fallacies of demanding perfection and damnation of self are exemplified by his perceived need to be in control, hence the distress caused by his "lack of control" over his cocaine use. The fallacy of demanding perfection can often lead to what Friedrich Nietzsche referred to as ressentiment. Men of ressentiment are, says Nietzsche, "cellar rats full of revenge and hatred" and conceals "a whole, vibrating realm of subterranean revenge" (in Leiter, 2002, p 203). Brian Leiter (2002) describes the psychological state of ressentiment as one produced by "a state of affairs that is both unpleasant to the affected person and one which he is powerless to alter through physical action." (p. 202). In Leiter's definition we see here how perceived loss of control is related to ressentiment. Nietzsche's dealt with the notion of ressentiment is his book The Genealogy of Morality and his book can be considered therapeutic (see step 6) as it discusses this issue and points out how to combat it (Danto, 1994; Goldie, 2000).

\section{Step Three: Refute any fallacy}

For this step I applied a Socratic approach to help Alwin see why his premises are irrational. I helped him to see how control is a central construct in addictive dynamics, and how it is unrealistic to have a perfectionistic demand for control.

I explained that Ulman and Paul (2006), in their book The Self Psychology of Addiction and its Treatment: Narcissus in Wonderland, indicate how at the core of addiction dynamics, there is a narcissistic fantasy of having an unrealistic sense of control of oneself, others and things/events in the world:

In the case of addiction, such a narcissistic fantasy centers on a narcissistic illusion of a megalomaniacal being that possesses magical control over psychoactive agents (things and activities). These latter entities allow for the artificial alteration of the subjective reality of one's sense of one's self and one's personal world. Under the influence of these intoxicating fantasies, an addict imagines being like a sorcerer or wizard who controls a 
International Journal of Philosophical Practice Volume 5, Number 1, Winter 2019

magic wand capable of manipulating the forces of nature - and particularly the forces of human nature. Eventually, a person becomes a captive of these addictive fantasies and then becomes an addict, lost in a wonderland. (p. 6)

In helping Alwin to refute his fallacies of demanding perfection and damnation of self I explained to him that there are various aspects of our being-in-the-world in which we are not in control, and this is not to be understood as negative or something to be ashamed about - but rather as something which makes us human.

\section{Step Four: Identify the Guiding Virtue for each fallacy}

Even though a counselee on an intellectual level is able to see the fallacies in his emotional reasoning this does not mean that he may still not be prone to acting out the deeply ingrained irrational arguments. At this stage of the process the value of identifying a guiding virtue for each fallacy is to provide a counterpoint to achieve sustainable change in emotional reasoning and behaviour. LBT provides a guiding virtue for each of the cardinal fallacies that are designed to counteract it.

Cohen (n.d.) states that these "virtues are aspirational in character and therefore not duties that set down the barebones of requirement. They are rational "oughts" rather than "musts"; they challenge counselees to strive toward realization of what is excellent in human reality. They are ideals, however, and never fully actualizable. They are long-term, life aspirations, wherein there can be both progress and backsliding” (p. 11).

For demanding perfection the corresponding guiding virtue is metaphysical security, which is the ability to accept imperfections in reality and for damnation of self it is self-respect. In the case of Alwin, this meant that he needed to stop trying to control things that are beyond his control and instead focus on what he can actually control, and need not lose his self-respect as a consequence.

In certain cases, cognitive dissonance may be so great when fallacious thinking is refuted that it can threaten the stability of the self and could in extreme cases lead to fragmentation and annihilation of the self. Consequently, the value of replacing faulty beliefs with guiding virtues cannot be overstated. According to Kohut (1977) the unconscious impulses and fantasies, that typically and historically have been the focus of psychoanalytic work, were seen by him as merely a defense against a deeper fear of disintegration and fragmentation of the self. He is of 
the opinion that selfobject functions provide the fortification against fragmentation. Although the original selfobjects are the organizing functions provided by the child's caregivers, as adults we also tend to form organisations with a wide variety of linguistic, cultural, image-based and behavioral selfobjects (Kohut, 19977). He implied that the threat of fragmentation (when deeply held beliefs are challenged) may be ever-present, even in relatively healthy personalities even after a cohesive self has been established. Furthermore, Kohut indicated that fragmentation anxiety may emerge at crucial moments of psychic change, when an existing maladaptive selfobject organisation is about to be given up. Pathological structures or patterns of objectrelating and systems of beliefs may be clung to because change may threaten fragmentation of the self. Thus, dysfunctional internal working models of relationships, as well as irrational systems of belief may be tenaciously retained because these structure the person's experience.

It is the background of the perceived threat of annihilation that guiding virtues can help counselees slowly change maladaptive beliefs for more adaptive beliefs without significant threat to the stability of the self.

Guiding virtues as a prophylactic against ideological possession. I have previously propose that ideologies are psychoactive and potentially addictive (Du Plessis, 2018). I suggest that 'ideology addiction' can be understood as a type of ideological possession and zealotry, with deleterious consequences for the individual and society. An individual in the grips of an ideology addiction exhibits psychological and behavioral patterns common to all addicted populations (It must be noted that I am not proposing that all individuals that adhere to an ideological systems is 'ideologically possessed', but instead am referring to an extreme position of ideological belief).

From a psychodynamic perspective, ideology addiction can be understood as the result of a narcissistic disturbance of self experience and deficits in self capabilities. Simply put, from a psychodynamic perspective ideology addiction can be understood as a pathological relationship to an ideology that provides a misguided solution to narcissistic injury and shame. Consequently, the activism of an ideology addict is fundamentally a narcissistic project. A misguided attempt at self repair and satisfaction of archaic narcissistic needs, and seldom motivated by the ideals of the ideology. From a self psychology perspective, narcissistic injury can lead to porous or scant psychic structure that is in constant threat of psychic fragmentation or annihilation. The individual with narcissistic injury often seeks self-objects that provide psychic scaffolding (Kohut, 1971, 1977). Ideology can be understood as self-object that provides much needed psychic structure for such individuals, and transports them in a transmogrified fantasy world. 
International Journal of Philosophical Practice Volume 5, Number 1, Winter 2019

The individual who is ideologically possessed is a "narcissist in wonderland" under the influence of "intoxicating fantasies" (Ulman \& Paul, 2000) that presents a danger to him or herself and society.

For example, in the context of the extreme political ideologies I will argue that there is narcissistic transference (idealized, mirroring and twinship transference) at play as a causal factor in determining an individual's choice of extreme political positions. For example although extreme 'left' political ideologies, like Communism, and extreme 'right' political ideologies, like National Socialism, presents itself conceptually as two opposing ideological positions, from a psychological perspective I will argue that the logical and conceptual content of these ideological positions are superfluous, as the psychological dynamics that motivates both its adherents are similar. At the roots lies a form or archaic narcissism that leads to the mode-of-being of ressentiment (in the Nietzschean sense) and a yearning for a future utopia, and what distinguishes the extreme left from the extreme right is the type of narcissistic transference each applies to sooth their unstable inner worlds.

To elucidate the above hypothesis I will apply a typological perspective. There are many typological perspectives that can be applied in the context of addiction. One example is that of feminine and masculine types. "When we speak of 'masculine' and 'feminine' we are not necessarily speaking of biological 'male' or 'female', but rather referring to a spectrum of attitudes, behaviors, and cognitive styles. I have proposed that psychoactive substances can be classified according to a masculine or feminine typology (Du Plessis, 2018). Depressants or downers such as tranquilizers, and heroin can be classified as 'feminine psychoactive substances'. And stimulants or uppers such as cocaine and methamphetamine can be classified as 'masculine psychoactive substances' (Du Plessis, 2010, 2012a).

I will argue that that extreme left and right political ideologies can also be classified according to a similar typological continuum. For example on the one side of the continuum we have extreme the extreme left wing ideology of Communism on the one side and on the other side we have extreme right wing ideology of National Socialism. Although they represent two extreme poles on the political spectrum, there are more similarities than differences. As Sir Rodger Scruton (2016) states in his book Fools, Frauds and Firebrands that "the public ideology of communism is one of equality and emancipation, while that of fascism [for example National Socialism] emphasizes distinction and triumph. But the two systems resemble each other in all other aspects...” (p. 201). I will classify extreme left ideologies like communist as a 
'pathological feminine ideology' of "equality and emancipation" and extreme right ideologies like fascism as a "pathological masculine ideology" of "distinction and triumph". Like Scruton (2016) I will argue that there is a "deep structural similarity between communism and fascism, both as theory and as practice" and to think otherwise "is to betray the most superficial understanding of modern history...Communism, like fascism, involved the attempt to create a mass popular movement and a state bound together under the rule of a single party, in which there will be total cohesion around a common goal...Both aimed to achieve a new kind of social order, unmediated by institutions, displaying an immediate and fraternal cohesiveness (p. 200201).

To elucidate a typology perspective of substance use disorders and ideology addiction I will apply the bioself-psychological typology of addiction of Ulman and Paul (2006). Kohut, (as cited in Ulman and Paul, 2006) stated: "The self should be conceptualized as a lifelong arc linking two polar sets of experiences: on one side, a pole of ambitions related to the original grandiosity [feminine] as it was affirmed by the mirroring self-object, more often the mother; on the other side, a pole of idealizations [masculine], the person's realized goals, which, particularly in the boy though not always, are laid down from the original relationship to the self-object that is represented by the father and his greatness" (p. 30). In Ulman and Paul's bioself-psychological typology, addiction is understood as a psychological end result of developmental arrest in the bipolarity of the formation of the self. Biological psychiatrists, in their conception of bipolar spectrum disorder, devote considerable attention to depression and mania as they manifest in this disorder. These mood disorders correlate with disorders of the bipolar self as understood by Kohut. He stated, "In general, a disturbance in the pole of grandiosity [feminine] may find expression in either an empty, depleted depression or, in contrast, in over-expansive and overexuberant mania or hypomania; whereas a disturbance in the pole of omnipotence [masculine] may appear in either depressive disillusionment and disappointment in the idealized or, in contrast, in manic (or hypomanic) delusions of superhuman physical and/or mental powers. We maintain that an individual maybe subject to specific outcomes resulting from a disturbance in either or both of these poles of the self" (in Ulman \& Paul, pp. 395-396). Owing to the specific accompanying mood disorder of each of the possible disturbances of the poles of the self, individuals will be attracted to certain psychoactive substances and ideologies, which can be understood as an attempt at rectifying a specific deficit in self and coping style (Ulman \& Paul, 2006). 
International Journal of Philosophical Practice Volume 5, Number 1, Winter 2019

Therefore, by using the masculine and feminine typology, we could propose that the psychopharmacological properties of certain classes of psychoactive substances and the psychoactive effect of ideologies correlate with masculine and feminine typologies (i.e., depressant psychoactive substances and extreme left ideologies of "equality and emancipation" with the feminine, and stimulant psychoactive substances and extreme right ideologies of "distinction and triumph" with the masculine), and how Kohut's (1977) poles of the self can also be classified within a masculine and feminine typology (pole of grandiosity/feminine and pole of omnipotence/masculine).We can, therefore, see how certain masculine/feminine psychoactive substances and masculine/feminine ideologies act as a structural prosthesis and a narcissistic object for transference in an attempt to rectify dysfunctional masculine and/or feminine poles of the self and coping styles. In short, extreme left ideologies of "equality and emancipation" (feminine) is a source for mirroring transference, and extreme right ideologies of "distinction and triumph" (masculine) is a source for idealized transference, and both provide a source for twinship transference.

According to Scruton the " $[\mathrm{m}]$ ost important is the way in which ideology of the kind I discuss [in Fools, Frauds and Firebrands] insulates itself against criticism, regards non-believers as a threat, and refuses to examine evidence coming from outside the closed circle of gratifying ideas" (personal communication, 5 August 2018). I would ascribe that "burying one's head in the sand" phenomenon (so typical of the ideologically possessed) as a protective mechanism against 'narcissistic mortification'. For this type of narcissistically disturbed individual the ideology serves the dynamic function of a 'psychic prosthesis' for a feeble and unstable self, and therefore a threat to the coherence of the ideology is experienced as an direct attack on the self, and conjures up powerful archaic fears of psychic fragmentation and annihilation. Therefore, to maintain psychic homeostasis the ideologically possessed individual must do everything in his power to refute these "attacks of reality" and eliminate the threat (often violently), or face a profoundly disturbing and frightening emotional experience (which perhaps could help explain the bizarre and elaborate mental gymnastics performed by many radical leftist "intellectuals" in their defence of Communist dictators like Joseph Stalin and Mao Zedong even after they were clearly exposed as brutal mass murderers).

Simply put, the application of guiding virtues, as well as the analysis of faulty thinking, is surely a powerful prophylactic against extreme ideologic positions which by default will be 
based on fallacious premises. And with the current political polarisation that is gripping the US, and indeed also in much of the rest of the world, it seems to be a much needed.

\section{Step Five: Find a Philosophy for the Guiding Virtue}

Once guiding virtues have been identified it points the way for choosing philosophical perspectives which can provide antidotes to the fallacious beliefs, as well as a vehicle for promoting these guiding virtues. Cohen (n.d.) states that the "appropriateness of a given philosophy for a counselee will depend, in part, on whether it is congenial, that is, consistent with other beliefs in the counselee's belief system. A congenial philosophy needs to align with the guiding virtue that is keyed to and counteracts a given fallacy" (p. 11).

As a philosophical perspective for both the guiding virtues of metaphysical security and self-respect, I selected aspects of 12 Step philosophy and existential philosophy that can provide an antidote to demanding perfection and damnation of self.

The existential given of freedom (and its limitations). The concepts of freedom and powerlessness are frequently used in addiction treatment and recovery groups. Freedom is mostly considered a positive state to strive for, and powerlessness as something to be avoided. Yet it is not that simple. Temple and Gall (2016) said that:

In the existential sense, freedom means to be distinct from external structures however, this leads to being engrossed by dread (Yalom, 1980) or angst (Langdridge, 2013).

Human beings desire structure and experience a sense of being ungrounded when confronted with freedom. (p. 9)

May (1981) believed that freedom can enhance our lives or it can cause one to escape and regress from the "dread" or "angst" that it may bring forth. This perspective emphasizes the unique experiences and needs of each individual, and the responsibility each of us has for our choices and what we make of our lives. South African philosopher and statesman Jan Smuts' theory of Holism - in its application to the human personality — is aligned with an existential view of freedom. ${ }^{15}$ The striving toward freedom is an essential and central component of Smuts' view of human nature (Du Plessis \& Weathers, 2015). Smuts (1926) asserts that:

\footnotetext{
15 Although the concept of holism has been implied by many thinkers, the term holism, as academic terminology, was first introduced and appeared publicly in print, by General Jan Smuts (1926) in his book Holism and Evolution. He writes that: "Holism (from o $\lambda \mathrm{o} \varsigma=$ whole) is the term here coined for this fundamental factor operative towards the creation of wholes in the universe" (p. 86).
} 
International Journal of Philosophical Practice Volume 5, Number 1, Winter 2019

To be a free personality represents the highest achievement of which any human being is capable. The Whole is free, and to realize wholeness or freedom (they are correlative expressions) in the smaller world of individual life represents not only the highest of which the individual is capable, but expresses also what is at once the deepest and highest in the universal movement of Holism. (p. 321)

Addiction can be understood as a lifestyle that severely constricts freedom, whereas a recovery lifestyle allows for a fuller expression of freedom and wholeness in our being-in-theworld (Boss, 1983). Even though a person might have a condition that limits their free will in relation to their addiction, known as powerlessness in recovery circles, it does not make them powerless over the choices they make, but they have to get the right support and to follow practices that will prevent them from regressing into this powerless condition. A person has the free will to make choices that support either a recovery lifestyle or an addictive lifestyle.

While existential philosophy and psychology applauds the notion of freedom, it also acknowledges limitations of our freedom. The notion of existential limitations has significance in the context of addiction and recovery. From one perspective, addiction can be understood as an attempt to bypass certain of our inherent limitations. While in active addiction, an individual tries to control the uncontrollable, in an attempt to avoid and medicate natural human experiences of pain, disappointment, boredom, and so forth. Ironically, this attempt at control ends up with a person being more out of control; enslaved by the medium which they use to try and control what ultimately cannot be controlled. Flores (1997) pointed out that, "Powerlessness over alcohol and the acceptance of one's limitation in relation to alcohol serves as a prototype for the alcoholic facing and accepting other limitations of the human condition" (p. 273).

Kurtz (1982) is of the opinion that AA works because it shares and addresses many features found in existential philosophy. As mentioned previously, a prominent theme in existential philosophy is the realization that, as humans, we exist within limitations. Being confronted by our limitations "engenders the dread, fear, and trembling of Kierkegaard, the angst of Heidegger, the angoisse of Sartre, and the abyss of Burber" (Flores, 1997, p. 274). By admitting their powerlessness over alcohol in Step One, they recognize and admit this fundamental limitation.

Apart from the acceptance of this limitation, AA requires alcoholics to share this limitation with other alcoholics. "The invitation to make such a connection with others and the awareness of the necessity of doing so arise from the alcoholic's very acceptance of limitation” (Kurtz, 1982, p. 53). 
Although AA suggests the acknowledgment of limitation, it does not abdicate the alcoholic of responsibility.

The existential given of suffering. A common theme in existential philosophy and 12 Step philosophy is the problem of suffering. AA recognizes suffering as an innate aspect of existence, with potential positive influence on our lives. In the context of AA, suffering is given meaning because it creates impetus in the alcoholic to question his or her existence and to be open for change. Viktor Frankl (1953) believed that when we can place our suffering within some meaningful context, we are not defeated by it, but are helped to transcend it. Similarly, in AA members share "the kinship of suffering" and recovery depends on the mutual sharing of suffering. AA teaches the alcoholic that to be fully human is to need others, and provides alcoholics with a universally shared explanation for their suffering.

From a Buddhist perspective, suffering or $d u k k h a$ is caused by our unwillingness to accept the world as it is and our insistence on trying to make it fit our expected ideas or fantasies. Addiction is, in essence, a refusal to accept things as they are and an attempt to avoid the reality of necessary suffering. An important aspect of recovery is realizing the inevitability of suffering and learning how to cope with it in a healthy way. Happiness is earned only through hard work - not through instant gratification. Flores (1997) summed up this existential predicament of the alcoholic:

Many existential writers believe that in such a confrontation between the realistic acceptance of the world as it is and the self-centered demands for unlimited gratification, reason would prevail and the individual would choose more realistically between the alternatives - continued unhappy struggles with old patterns of expectations or authentic existence with expanded freedom of choice and responsible expression of drives and wishes. With Socrates, we argue to 'know thyself.' In this fashion, AA members are taught to believe that the authentic existence advocated by the AA program holds the key to self-examination, self-knowledge, emancipation, cure, and eventual salvation. (p. 280)

\section{Step Six: Apply the philosophy}

In the previous stages the counselee developed the philosophical and conceptual foundation to make positive changes in their behavioural and emotional responses. However, there still very likely a cognitive dissonance present between the counselee's new rational way of 
thinking and ingrained irrational beliefs. Cohen (1) explains that step six of LBT consist of a further three sub-steps: (1) identifying the counselee's behavioural reasoning, (2) building a plan of action, and (3) implementing the plan of action.

Identifying the Counselee's Behavioral Reasoning. Cohen (n.d.) explains that in this sub-step "the behavioral implications of the counselee's irrational beliefs need to be carefully unpacked and a behavioral plan of action based on the counselee's new antidotal wisdom needs to be created. In other words, there needs to be behavioral as well as cognitive changes" (p. 16). In unpacking Alwin's behavioral reasoning and I helped him to see what he is deducing in the way of prescribed actions from his conclusion. This behavioral reasoning takes the form of a behavioral prescription $(\mathrm{P})$ deduced from the justification $(\mathrm{J})$ and a behavioral rule (If $\mathrm{J}$ then $\mathrm{P}$ ):

If $\mathrm{J}$ then $\mathrm{P}$

$\mathrm{J}$

So, P, Thus:

(Behavioral Rule) When I cannot control something, I must regain control.

(Justification) I am out of control

(Behavioral Prescription) So I should try harder and regain control.

Building a Plan of Action. As part of step six a plan of action will be agreed upon that is based on the philosophies that were chosen in the fifth step. That is, an opposing set of behavioural rules can be deduced from the philosophy.

In the above interchange I helped Alwin to draw out the implications of 12 Step and existential philosophy in building a plan of action. In short, I helped Alwin to construct behavioral reasoning using 12 Step and existential philosophy as major premises:

(Behavioral Rule) If you feel out of control, then decide if you can or not control this specific area of your life.

(Justification) You feel out of control.

(Behavioral Prescription) So, you when you can't control a specific situation you can accept that it is out of your control

And:

(Behavioral Rule) If you prefer to be in control then you should not base your self-esteem on whether you are in control or not.

(Justification) You prefer to be in control. 
(Behavioral Prescription) So, you should acknowledge this is just a preference and not demand that you are in control.

Implementing the Plan of Action. This state of cognitive dissonance between the first two rational syllogisms and the third irrational one can be resolved by building and exercising willpower. It is important to note the ontological emphasis that LBT places on willpower. While the Sarteian notion of radical freedom is obviously outdated and naïve, it is equally naïve to adopt a radical deterministic position. LBT acknowledges the notion of irrational psychodynamic forces and behavioural patterns, as well as socio-political influences on behaviour, the fact that we have personal agency means that to an significant extent we can change our emotional and intellectual worlds and thereby have control over our behaviour. It would be useful to briefly discuss the implications of a deterministic view in the context of addiction to point out the value of willpower as part of a treatment strategy.

\section{Willpower as antidote to deterministic bias in understanding addiction. Socially} deterministic approaches to addiction has increasingly gained traction. I would ascribe this phenomenon to the rising influence of social justice perspectives in the human and social sciences. This view or rather ideology holds a radically deterministic view of addiction (and human nature), based on the premise that social pathologies are addiction's 'root cause'. The pitfall here is when social factors, which of course contribute to patterns of drug use, are considered determinate. ${ }^{16}$

Social justice proponents often operate with over-simplified dichotomies of power and status, such as 'oppressor/privileged' and 'oppressed/non-privileged' (Peterson 2018), and present a socially deterministic framework where drug abuse has been identified as a symptom of various types of inequalities (Peralta and Jauk, 2011). It introduces a new moralism by suggesting that problematic drug use might be a 'rational' response to (in some cases generalized) social victimhood. Social justice proponents epistemologically prioritize 'social inequality' in which the individual drug user is the hapless victim of an unfair, deficient or

\footnotetext{
${ }^{16}$ It is not just in the field of addiction that there is a push to politicize mental health debate and interventions but also in the field of psychology (see the Federal Action Network of the American Psychological Association, 2014) "where some have argued that the field's ethical commitments to social justice requires psychologists to expand their professional activities to political domain" (Allen \& Dodd 2018, p. 42). It is hard to find the words to adequately describe the farcicality of the proposition that psychologists are ethically required "to expand their professional activities to political domain" (Allen \& Dodd 2018, p. 42). It is obviously absurd and unethical to force psychologists to participate in debate in an arena (political science and political philosophy) in which they have received no exposure as part of their training. I consider it equally unethical and deplorable for a psychologist or any mental health professional to impose their political or religious ideology onto their clients, which is exactly what the 'social justice counselling' orientation promotes.
} 
exploitative world. But, as Mugford \& OMally (1991), state, "such a [socially] deficit model must be considered against the fact that the fastest growth in drug use arose [in many parts of the world] in the affluent 60 s and 70 s...It was the privileged in search of pleasure, not the underprivileged in search of escape who provided the impetus for the development of large-scale cocaine trade" (p. 24). They go on to say that social inequality and pathology "is associated with certain kinds of psychotropic drug use in the present period, but it is neither a necessary nor sufficient condition for such use" (p. 24). The truth is that addiction and drug use is a "great equalizer' and cut across all boundaries and identities of class, gender, sexuality, race, culture and religion.

Nobody would deny that there are socio-economic factors that influence an individual's behaviour. But when we adopt a deterministic view of human existence we risk conceptualizing individuals as being without agency or without the resilience to overcome obstacles, and thus do injustice to human nature and the individuals we purport to help. A socially deterministic view of addiction implies that individuals have little or no free-will, are psychologically homogenous, and are at the mercy of their environment. Most crucially, by adopting a socially determined view the consequent solutions will be equally socially determined and at odds with many of our basic human rights. A socially deterministic view of recovery or harm reduction has obvious appeal to governments and pharmaceutical corporations. Personal responsibility and agency has no market value, but a victim can be sold many 'external solutions' to his/her 'problem', whether through social engineering or pharmaceutical interventions.

Behavioural recommendations. As part of Alwin's LBT behavioural protocol I suggested bibliotherapy. I recommended two books for Alwin: (1) On The Genealogy of Morality by Friedrich Nietzsche (1998) and (2) Spirituality of Imperfection: Storytelling and the Search for Meaning by Ernest Kurtz \& Katherine Ketcham (1993). These readings can assist Alwin in reinforcing his behavioural prescription developed earlier in this step.

I also suggested Alwin continues working his 12 Step program with his 12 Step sponsor as many of the attitudinal practices (spiritual principles) shares similarities with the guiding virtues discussed so far.

\section{Conclusion}

In this essay I argued for the utility of including an existential perspective when attempting to develop an comprehensive understanding of addiction and its treatment. The existential 
perspective discussed in this essay was informed by existential philosophy, existential phenomenology, existential psychology, and existential therapy. In then presented a case study and outlined the application of the six steps of LBT in dealing with existential issues that arose presented in the counselling session.

This essay presented one aspect of the utility of LBT in the treatment of addiction, and there are many more areas in which it would be useful, for example dealing with irrational beliefs that sustain addictive dynamics. LBT is a promising methodology as part of an integrated approach to treatment and more studies are needed to explore its full potential in the treatment of addiction and recovery coaching.

\section{Acknowledgements}

The author would like to thank Dr. Elliot Cohen for constructive criticism of the manuscript. A portion of this essay was previously published in my book An Integral Foundation for Addiction Treatment: Beyond the Biopsychosocial Model (Du Plessis, 2018). 
International Journal of Philosophical Practice Volume 5, Number 1, Winter 2019

\section{References}

Allen, L. R. \& Dodd, C. G. (2018). Psychologists' responsibility to society: Public policy and the ethics of political action. Journal of Theoretical and Philosophical Psychology, 38(1), 42-53.

American Psychiatric Association (2013). Diagnostic and statistical manual of mental disorders (5th ed.). Arlington, VA: American Psychiatric Publishing.

American Psychological Association (2014). Retrieved from http:/www.apa.org/pi/gr/2014advocacy-activities.aspx

Bhaskar, R. (1997). A Realist Theory of Science. 2nd edition London: Verso.

Bhaskar, R. (1998). The possibility of naturalism: A philosophical critique of the contemporary human sciences. 3rd edition Critical Realism Interventions Series. London: Routledge.

Boss, M. (1983). The existential foundations of medicine and psychology. New York: Jason Aronson.

Cohen E. D. (n.d.) Primary training workshop in Logic-Based Therapy (LBT). Institute of Critical Thinking.

Cohen, E. D. (2003). What would Aristotle do? Self-control through the power of reason. New York: Prometheus Books.

Cohen, E. D. (2007). The new rational therapy: Thinking your way to serenity, success, and happiness. Lanham, MD: Rowman \& Littlefield.

Cohen, E. D. (2013). Theory and practice of Logic-Based Therapy: Integrating critical thinking and philosophy into psychotherapy. New York: Cambridge Scholars Publishing.

Cooper, M. (2003). Existential therapies. London, England: Sage.

Danto, A. C. (1994). Some remarks on The Genealogy of Morals in Nietzsche, Genealogy, Morality: Essays on The Genealogy of Morals, ed. Richard Schact (University of California Press).

DiClemente, C. C. (2003). Addiction and change: How addictions develop and addicted people recover. New York: Guilford Press.

Du Plessis, G. P. (2010). The integrated recovery model for addiction treatment and recovery. Journal of Integral Theory and Practice, 5(3), 68-87. 
Du Plessis, G. P. (2012a). Integrated recovery therapy: Toward an integrally informed individual psychotherapy for addicted populations. Journal of Integral Theory and Practice, 7(1), 124148.

Du Plessis, G. P. (2012b). Toward an integral model of addiction: By means of integral methodological pluralism as a metatheoretical and integrative conceptual framework. Journal of Integral Theory and Practice, 7(3), 1-24.

Du Plessis, G. P. (2013). The import of integral pluralism in striving towards an integral metatheory of addiction. Paper presented at the Third Biennial Integral Theory Conference, CA: San Francisco, 20 July.

Du Plessis, G. P. (2014a). Towards an integral metatheory of addiction. Master's Dissertation. University of South Africa.

Du Plessis, G. P. (2014b). An integral ontology of addiction: A multiple object existing as a continuum of ontological complexity. Journal of Integral Theory and Practice, 9(1), 38-54.

Du Plessis, G. P. (2015). An Integral guide to recovery: Twelve Steps and beyond. Integral Publishers: AZ, Tuscan.

Du Plessis, G. P. \& Weathers, R. (2015). The Integral Jan Smuts. Paper Presented at the Fourth International Integral Theory Conference: JFK University, CA: San Francisco, 19 July.

Du Plessis, G. P. (2018). An integral foundation for addiction and its treatment: Beyond the biopsychosocial model. Integral Publishers: AZ, Tuscan.

Ellis, A. (1994). Reason and emotion in psychotherapy: Comprehensive method of treating human disturbances: Revised and Updated. New York, NY: Citadel Press.

Fields, R. (1998). Drugs in perspective. Boston: McGraw-Hill.

Flores P. J. (1997). Group psychotherapy with addicted populations. Binghamton, NY: The Haworth Press.

Frankl, V. (1953). Man's search for meaning. Boston, MA: Beacon.

Glasser, W. (1965). Reality therapy. A new approach to psychiatry. New York: Harper \& Row.

Goldie, P. (2000). Emotions. Oxford University Press. 
Gordis, E. (2000). From genes to geography: The cutting edge alcohol research. Alcohol Alert, 48. Rockville MD: National Institute of Alcohol and Drug Abuse.

Griffiths, M. D. (2005). A components model of addiction within a biopsychosocial framework. Journal of Substance Use, 10, 191-197.

Hacking, I. (1999). The social construction of what? Harvard: Harvard University Press.

Harre, R., \& Moghaddam, F. M. (2012). Psychology for the third millennium: Integrating cultural and neuroscience perspectives (New York edition) SAGE Publications.

Hayes, S. C., \& Smith, S. (2005). Get out of your mind and into your life: The new acceptance and commitment therapy. Santa Rosa, CA: New Harbinger Publications.

Heidegger, M. (1927/1962). Being and time. Trans. John Macquarrie and Edward Robinson. New York: Harper.

Hill, W. B. (2010) An ontological analysis of mainstream addiction theories: Exploring relational alternatives. Retrieved April, 2017, from http://search.proquest.com//docview/305185322

Ho, S. S. and Nakamura, Y. (2017). Healing dysfunctional identity: Bridging mind-body intervention to brain systems. Journal of Behavioral and Brain Science, 7, 137-164.

Husserl, E. (1901/1973). Logical investigations. Trans. J. N. Findlay, London: Routledge.

Kierkegaard, S. (1954). The sickness unto death. New York, NY: Doubleday. (Original work published 1849).

Kohut, H. (1971). The analysis of the self: A systematic approach to the psychoanalytic treatment of narcissistic personality disorders. New York, NY: International University Press.

Kohut, H. (1977). The restoration of self. New York, NY: International University Press.

Kurtz, E. (1982). Why AA works: The intellectual significance of Alcoholics Anonymous. Quarterly Journal of Studies on Alcohol, 43, 38-80.

Kurtz, E., \& Ketcham, K. (1993). The spirituality of imperfection: Storytelling and the search for meaning. New York, NY: Bantam Books.

Leiter, B. (2002). Nietzsche on Morality. New York: Routledge. 
International Journal of Philosophical Practice Volume 5, Number 1, Winter 2019

Linehan, M. M. (1993). Diagnosis and treatment of mental disorders. Cognitive-behavioral treatment of borderline personality disorder. New York, NY, US: Guilford Press.

McEvoy, P. M., Nathan, P., \& Norton P. J. (2009). Efficacy of transdiagnostic treatments: A review of published outcome studies and future research directions. Journal of Cognitive Psychotherapy, 23, 20-33. http://dx.doi.org/10.1891/0889-8391.23.1.20

May, R. (1953). Man's search for himself. New York, NY: Dell.

Miller, W. R. \& Rollnick, S. (2002). Motivational interviewing: Preparing people to change. New York: Guilford Press.

Miller, W. R. (2006). Motivational factors in addictive behaviors. In W.R. Miller \& K. M. Carroll (Eds), Rethinking substance abuse: What the science shows, and what we should do about it (134-152). New York: Guilford Press.

Mugford, S. K. \& O’Malley, P. (1991). Heroin policy and deficit models: The limits of Left Realism. Crime, Law and Social Change, 15,(1), 19-36.

Nietzsche, F. (1998). On the genealogy of morality, translated by Maudemarie Clark and Alan J. Swenson, Indianapolis, IN: Hackett.

Peralta, R. L. \& Jauk, D. (2011). A brief feminist review and critique of the sociology of alcoholuse and substance-abuse treatment approaches. Sociology Compass, 5(10), 882-897.

Peterson, J. (2018). 12 rules for life: An antidote to chaos. Toronto, Canada: Random House.

Ribes-Inesta, E. (2003). Concepts and theories: Relation to scientific categories. In K.A. Lattel \& P.N. Chase (Eds.), Behavior theory and philosophy, (pp.147-166). New York: Kluwer Academic/Plenum.

Richardson, F. C. (2002). Current dilemmas, hermeneutics, and power. Journal of Theoretical and Philosophical Psychology. 22, 114-132.

Richardson, F. C. (2005). Psychotherapy and modern dilemmas. In B.D. Slife, F.C. Richardson \& J.S. Reber (Eds), Critical thinking about psychology: Hidden assumptions and plausible alternatives. Washington, D.C.: American Psychological Association.

Sartre, J. (1971). Being and nothingness. NewYork, NY: Bantam. (Original work published 1943). 
Shapero, B. G., Greenberg, J., Pedrelli, P., de Jong, M., \& Desbordes, G. (2018). Mindfulnessbased interventions in psychiatry. Focus (American Psychiatric Publishing), 16(1), 32-39.

Slife, B. D. \& Richardson, F. C. (2008). Problematic ontological underpinnings of positive psychology: A strong relational alternative. Brigham Young University, Provo, UT. University of Texas, Austin, TX.

Slife, B. D. (2005). Taking practice seriously: Toward a relational ontology. Journal of Theoretical and Philosophical Psychology, 24, 157-178.

Smuts, J. C. (1926). Holism and evolution. London: MacMillan.

Scruton, R. (2016). Fools, frauds and firebrands. New York: Bloomsbury Continuum.

Temple, M., \& Gall, T. L. (2016). Working through existential anxiety toward authenticity: A spiritual journey of meaning making. Journal of Humanistic Psychology, 1-26. doi:10.1177/0022167816629968

Ulman, R. B. \& Paul, H. (2006). The self psychology of addiction and its treatment: Narcissus in wonderland. New York: Routledge.

Wilber, K. (1995). Sex, ecology and spirituality: The spirit of evolution. Boston, MA: Shambhala.

Wilber, K. (2006). Integral spirituality: A startling new role for religion in the modern and postmodern world. Boston, MA: Integral Books.

Yalom, I. (1980). Existential psychotherapy. New York, NY: Basic Books. 